\title{
Double Barrel Shotgun Scanning of the Caveolin-1 Scaffolding Domain
}

\author{
Aron M. Levin ${ }^{\dagger, \|}$, Katsuyuki Murase ${ }^{\dagger, \|}$, Pilgrim J. Jackson ${ }^{\dagger}$, Mack L. Flinspach, Thomas L. Poulos ${ }^{\dagger, \neq, \S, \uparrow,}$

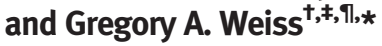

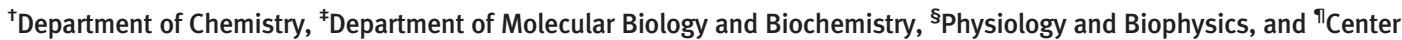 \\ in Chemical and Structural Biology University of California, Irvine, CA 92697. "These authors contributed equally to this \\ work.
}

U ncovering the forces governing receptor-ligand specificity and promiscuity remains a challenging problem. Extensive overlap exists among binding partners in the human protein-protein interactome, but our understanding of contributions by individual residues to such interactions remains sparse (1). One method for rapidly elucidating this critical information is phage-displayed shotgun scanning, either with alanine or with homologue substitutions $(2,3)$. Alanine shotgun scanning applies combinatorial libraries in which each examined position is substituted with a 1:1 ratio of alanine and the wild-type amino acid. Homologue shotgun scanning similarly employs either wildtype or a homologous amino acid substitution (e.g., substitution with a 1:1 ratio of phenylalanine and tyrosine).

The protein examined here, caveolin-1, binds and inhibits several signaling molecules, including adenyl cyclase, endothelial nitric oxide synthase (eNOS), and protein kinase $A$ (PKA) (4). This ability to regulate the activity of key signaling enzymes forms the basis for tumor suppressor activity by caveolin-1 $(5,6)$. Nitric oxide (NO) production is inhibited by caveolin-1 binding to both eNOS and neuronal nitric oxide synthase (nNOS) $(4,7)$. The region of caveolin-1 responsible for eNOS and PKA inhibition has been narrowed to the caveolin-1 scaffolding domain (CSD), which inhibits both proteins in a dose-dependent manner with an $\mathrm{IC}_{50}$ of 1-20 $\mu \mathrm{M}$ $(8-10)$. Constrained by the limitations inherent to membrane proteins, caveolin is less well studied than some multipartner binding proteins, such as calmodulin, which has hundreds of binding partners and dozens of crystal structures (11-14). For proteins with very little structural data, such as CSD, other techniques such as
ABSTRACT In the postgenomic era, a major challenge remains, elucidating the thermodynamic forces governing receptor-ligand specificity and promiscuity. We report a straightforward approach for mapping side-chain contributions to binding for the multipartner interactions characteristic of the human proteome. Double barrel shotgun scanning dissects binding to two or more targets through combinatorial mutagenesis of one protein binding to multiple targets. Examined here, the caveolin-1 scaffolding domain (CSD) binds to and inhibits both endothelial nitric oxide synthase (eNOS) and protein kinase A (PKA). Homolog shotgun scanning of CSD highlights residues responsible for CSD oligomerization and binding to eNOS and PKA. The experiments uncover a general mechanism in which CSD oligomerizes and deoligomerizes to modulate binding affinity to partner proteins. The results provide a detailed look at a multipartner protein interaction, uncovering strategies for one protein binding to multiple partners.
*Corresponding author, gweiss@uci.edu.

Received for review March 10, 2007 and accepted May 16, 2007.

Published online June 29, 2007 10.1021/cb700055t CCC: $\$ 37.00$

(c) 2007 American Chemical Society 
homologue shotgun scanning can identify residues important for binding to multiple partners (15).

Our ultimate goal is to leverage shotgun scanning techniques to dissect key cell signaling regulatory proteins with a focus upon proteins that are difficult to characterize structurally. Here, we report the first multibarrel shotgun scanning approach. The detailed knowledge of multipartner binding can uncover strategies for naturally occurring professional binding proteins, and, in turn, guide protein engineering efforts. A double barrel homologue shotgun scan of CSD binding to both PKA and eNOS uncovered key functionalities required for binding to the targets (Table 1). After the binding of individual phage-displayed mutants to PKA and eNOS

(Figure 1) was tested, synthetic CSD peptide enhanced phage-displayed CSD binding to PKA and eNOS

(Figure 2). Finally, we directly demonstrate the physical oligomerization of CSD peptides by dynamic light scattering (DLS) experiments. We propose that oligomerization of CSD can mediate higher affinity binding to signaling proteins. Furthermore, deoligomerization of CSD can release the signaling proteins and thus activates their enzymatic activity (Figure 3).

\section{RESULTS AND DISCUSSION}

Shotgun Scanning of CSD. In homologue shotgun scanning, combinatorial libraries with a close homologue and the wild-type residue substituted in specific positions are constructed to identify requirements for specific side-chain functionalities during selections for binding to a target receptor $(2,16)$. To identify key sidechain functional groups for binding to PKA and eNOS, a CSD homologue shotgun scanning library was designed with a theoretical diversity of $2^{20}\left(\sim 10^{6}\right)$. After electroporation, the constructed CSD library included a number of transformants well in excess of this theoretical diversity $\left(5.8 \times 10^{10}\right)$. Thus, the library likely included a complete set of all possible wild-type and homologous substitutions. All shotgun scanning experiments are subject to biases through phage amplification, selections for side-chain contributions to protein structure in addition to binding, and additional caveats (17).

After four rounds of selection for binding to either PKA or eNOS, functional variants of CSD from homologue shotgun scanning were identified by phage enzyme-linked immunosorbent assay (ELISA; Table 1 and Table 2). The relative binding affinities of selectants from the respective libraries were compared by

\begin{tabular}{|c|c|c|c|}
\hline \multirow[b]{2}{*}{ CSD } & \multicolumn{2}{|c|}{ Selection Ratio } & \multirow[b]{2}{*}{$\begin{array}{l}\text { Ratio }_{\mathrm{PKA}} / \\
\text { Ratio }_{\text {eNOs }}\end{array}$} \\
\hline & $\begin{array}{l}\text { PKA } \\
(n=135)\end{array}$ & $\begin{array}{l}\mathrm{eNOS}^{a} \\
(n=60)\end{array}$ & \\
\hline D82 & $0.4(E)$ & 0.1 & 4.0 \\
\hline G83 & 4.5 (A) & 3.0 & 1.5 \\
\hline 184 & $4.0(V)$ & 4.3 & 0.9 \\
\hline W85 & $1.8(\mathrm{~L})$ & 7.0 & $\underline{0.3}$ \\
\hline K86 & $12(R)$ & 16 & 0.8 \\
\hline A87 & $0.3(\mathrm{~S})$ & 0.7 & 0.4 \\
\hline S88 & $1.7(T)$ & 1.0 & 1.7 \\
\hline F89 & $22(Y)$ & 2.2 & 10.0 \\
\hline T90 & $0.3(\mathrm{~S})$ & 0.4 & 0.8 \\
\hline T91 & $0.2(S)$ & 0.7 & $\underline{0.3}$ \\
\hline F92 & $3.4(Y)$ & 3.0 & 1.1 \\
\hline T93 & $0.3(\mathrm{~S})$ & 0.7 & 0.4 \\
\hline V94 & $0.5(I)$ & 0.9 & 0.6 \\
\hline T95 & $0.2(S)$ & 0.3 & 0.7 \\
\hline K96 & $1.8(\mathrm{R})$ & 7.0 & 0.3 \\
\hline Y97 & $0.1(F)$ & 0.2 & 0.5 \\
\hline W98 & $3.5(L)$ & 2.2 & 1.6 \\
\hline F99 & $0.2(Y)$ & 1.0 & 0.2 \\
\hline Y100 & $1.2(\mathrm{~F})$ & 0.2 & 6.0 \\
\hline R101 & $0.6(K)$ & 1.3 & 0.5 \\
\hline
\end{tabular}

${ }^{a}$ Ratio of wild-type (wt) to homologue (H) for each selection with the homologous substitution listed in parentheses. Bold entries indicate strong selection for the wildtype side chain, and preference for the homologous mutation is indicated in bold italics. Values for $n$ indicate the number of unique CSD variants analyzed for each selection. ${ }^{b}\left(\mathrm{wt}_{\mathrm{eNOS}}{ }^{\star} \mathrm{H}_{\mathrm{PKA}}\right) /\left(\mathrm{wt}_{\mathrm{PKA}}{ }^{\star} \mathrm{H}_{\mathrm{eNOS}}\right)$. The ratio of ratios for the two selections. Values $>1.0$ indicate residues important for binding to PKA, and values $<1.0$ highlight side chains critical to binding to eNOS (underlined).

phage ELISA (Figure 1). Many CSD homologues from each library bound their targeted receptor with higher affinity than wild-type CSD, assuming similar levels of peptide display on the surface of the phage. For highly homologous peptides of identical length, this is a reasonable assumption supported by previous shotgun scanning studies (3); however, differences in display levels cannot be ruled out in these experiments. 
This enhanced binding trend through homologue shotgun scanning has also been observed for homologue shotgun scanning of elongation factor Tu ligands (16), engrailed homeodomain (18), and ortholog scanning (19). Homologue shotgun scanning can improve the affinity of displayed ligands through fine adjustments of sidechain functionality and competition during selections. Natural evolution applies a similar strategy. Inherent to the genetic code, single base mutations often result in homologous or conservative substitutions. Indeed, there are many successful examples of protein engineering through error-prone PCR, DNA shuffling, and mutator strains of Escherichia coli, which can leverage the power of single base changes leading to homologous substitutions (20). However, homologue shotgun scanning provides a focused method for revealing higher affinity sequences for a specific region of protein structure. Interestingly, no common sequences were selected among the PKA and eNOS binders. This divergence in binding sequences reflects the different receptor surfaces presented to the library during in vitro evolution. The results suggest that wild-type CSD may have been selected for binding weakly to dozens of ligands, rather than binding strongly to a single ligand.

Since both selections feature similar conditions with aliquots from the same library, results from the two shotgun scanning experiments can be directly compared. Preferences for specific wild-type CSD residues are listed as "selection ratios" for the wild-type to homologue substitutions from the selectants against each receptor (Table 1). Six wild-type amino acids, mainly clustered near the $\mathrm{N}$-terminus, (residues $83-86,89$, and 96) were well conserved as wild-type during selections against both targets.

At positions 82, 90, 91, 95, and 97, homologous substitutions were strongly preferred over wild-type in selections against both eNOS and PKA. CSD residues 91-93 were previously reported as being critical to assembly of caveolin-1 filaments but not to the heptameric oligomer formation (21). Homologue shotgun scanning showed preference for only one wild-type amino acid in this region, Phe92. However, since individual phagedisplayed CSD subunits are unlikely to oligomerize on the surface of phage, the oligomeric states of phagedisplayed CSD could differ from the cellular minimum oligomer unit of heptameric caveolin-1. However, as described below, addition of chemically synthesized CSD to the phage-displayed CSD allows reacquisition of the most thermodynamically favorable CSD assembly.

Residue 92 has been demonstrated as critical for both PKA (10) and eNOS inhibition (22). The latter report also identified the central residues of CSD (89-95; FTFTVT) as required for cellular eNOS inhibition through experiments with truncated CSD variants fused to a cellular permeabilization sequence. Additional residues deemed important, via alanine mutations, for inhibiting PKA activity were Phe89, Thr93, Trp98, and Phe99. Our homologue scan corroborates these data and provides additional insight. For example, PKA strongly preferred Phe89 over a homologous tyrosine substitution, demonstrating that a phenolic hydroxyl group disrupts CSD binding to PKA at position 89, and Trp98 was preferred over substitution with alkyl side chain of leucine. Con- 


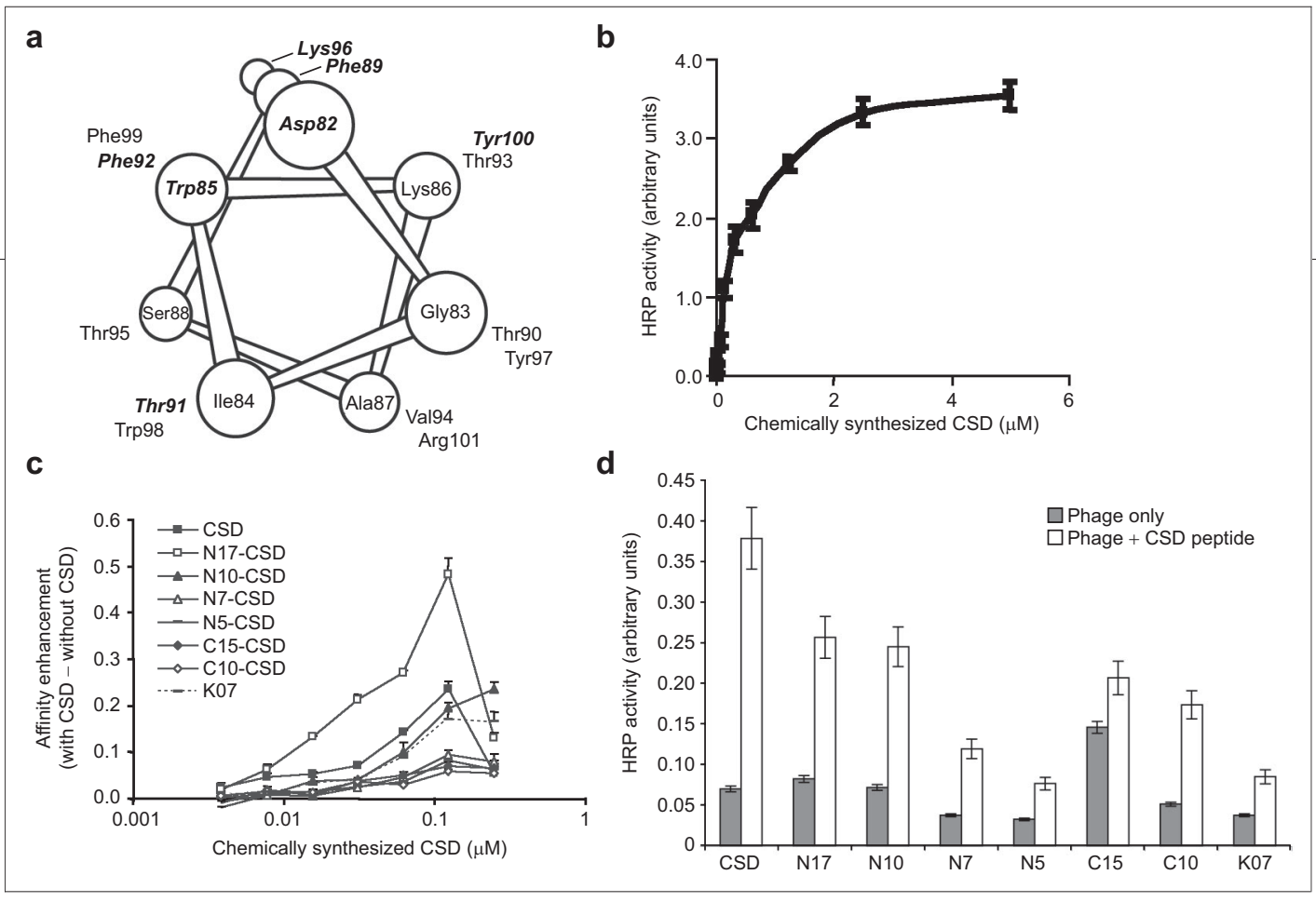

Figure 2. CSD binding and oligomerization. a) Helical wheel of CSD. The seven residues in bold italics correspond to the residues underlined in Table 1. These residues are on the face of the CSD helix most likely to bind both eNOS and PKA. b) Oligomer complementation. In this ELISA, a constant concentration of phage-displayed CSD (10 nM) was evaluated for binding to eNOS in the presence of the indicated concentration of chemically synthesized CSD. Error bars represent the standard error for the average of three experiments. An analogous experiment with PKA generated similar results (15). c) Oligomer complementation of truncated CSD variants binding to eNOS. Phage-displayed truncated CSD variants were incubated in eNOS-coated microtiter wells with the indicated concentrations of chemically synthesized CSD. Affinity enhancement indicates the difference in HRP activity upon addition of CSD peptide. d) Binding to PKA by truncated CSD variants. CSD variants were derived from truncation of $\mathrm{C}$-terminal or $\mathrm{N}$-terminal residues, as described in the text. The white bars represent ELISA binding by phage-displayed CSD variants with the addition of $5 \mu \mathrm{M}$ chemically synthesized CSD. versely, at the remaining two positions, homologous substitutions were slightly preferred, T93S and F99Y. A similar pattern emerged for CSD binding to eNOS, although a conventional alanine scan has not been previously reported.

Divergence in side-chain preferences for the two shotgun scanning targets can reveal different strategies for gaining binding affinity to specific binding partners. Such divergence can be uncovered through large deviaresidues mainly line one face of the $\alpha$-helix that our laboratory has previously predicted to interact with PKA (Figure 2, panel a). Taken together, the results implicate one side of the CSD helix in binding to both eNOS and PKA.

Oligomer Complementation. Enhancement of phage-displayed CSD binding to PKA by the addition of chemically synthesized CSD was first reported by our laboratory (15). We suspected that this enhance-

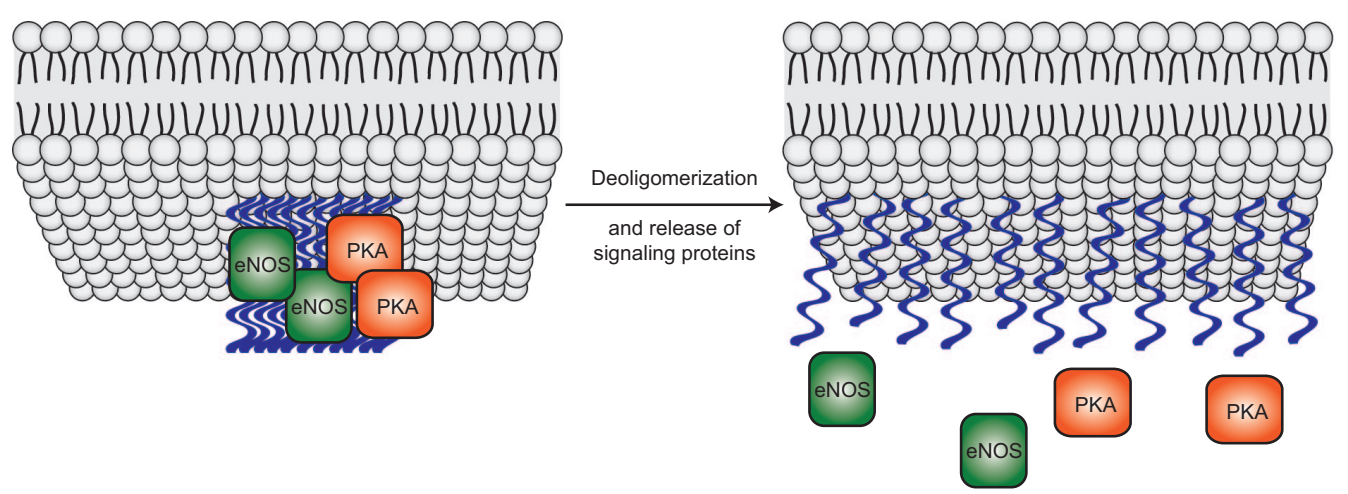

Figure 3. Schematic diagram illustrating how CSD can bind tightly to PKA and eNOS as oligomers and then release the proteins upon deoligomerization. 
ment was not unique to the CSD-PKA interaction and so performed a similar experiment with oligomer complementation of CSD binding to eNOS. Serial dilutions of synthetic CSD were incubated with a single concentration of phage-displayed CSD before assay for binding to eNOS (Figure 2, panel b). The resultant CSD oligomer bound in a dose-dependent manner with improved apparent affinity to eNOS at higher concentrations of added CSD. As expected, this affinity enhancement could be out-competed by addition of a large excess of synthetic CSD (last data point in Figure 2, panel c).

Direct Observation of Oligomer Formation. DLS confirmed the oligomer complementation experiments and illustrated the detailed information about side-chain and sequence requirements that the phage-based technique can provide over conventional approaches. Two CSD constructs, a fusion to maltose binding protein (MBP) and the free peptide, were analyzed by DLS. Fusion to MBP can often boost the solubility of aggregation-prone peptides, and CSD-MBP remained soluble, whereas free CSD aggregates in solution at high concentrations. At various concentrations, DLS of CSDMBP revealed a single species of very large oligomers having a hydrodynamic radius $\left(R_{\mathrm{H}}\right)$ of $28 \mathrm{~nm}$ and a polydispersity of $16 \%$, an observation consistent with the formation of higher order oligomers. Since CSD free peptide exhibits very low solubility, the addition of a small concentration of organic solvent was required for DLS. Solutions with $10 \%$ trifluoroethanol (TFE) also revealed high-order soluble oligomers with a $R_{\mathrm{H}}$ of $68 \mathrm{~nm}$. Also monomodal, the CSD oligomers exhibited a wider range of sizes with a polydispersity of $39 \%$. Since TFE can stabilize $\alpha$-helices, the CSD measurements were repeated in the presence of $5 \%$ DMSO, revealing even larger oligomers with $R_{\mathrm{H}}$ of $107 \mathrm{~nm}$ and polydispersity of $43 \%$. These results confirm that CSD forms large stable oligomers. However, oligomer complementation can provide a more detailed analysis of residues mediating the oligomeric interaction due to the expedience of manipulating, through mutagenesis and truncation, phagedisplayed proteins.

Deletion Mutagenesis and Oligomerization. Deletion mutagenesis explored contributions to PKA and eNOS binding by residues at the CSD N- and C-termini. Phagedisplayed truncated CSD peptides, N5-CSD (five $\mathrm{N}$-terminal amino acids), N7-CSD, N10-CSD, N17-CSD, C10-CSD (10 C-terminal amino acids), and C15-CSD

\begin{tabular}{|c|c|c|}
\hline Receptor & Label & Sequence $^{a}$ \\
\hline eNOS/PKA & wt-CSD & DGIWKASFTTFTVTKYWFYR \\
\hline \multirow[t]{9}{*}{ eNOS } & CV-1 & $\mathbf{E}----\mathrm{SA}-\mathrm{NS}-\mathrm{N}----\mathrm{L}---$ \\
\hline & CV-2 & $\mathbf{E}--\mathrm{L}--\mathrm{A}-\mathrm{NR}-\mathrm{SIS}-\mathbf{F}--\mathbf{F M}$ \\
\hline & CV-3 & $\mathbf{E}----S A Y-I Y S---\mathbf{S}-Y-K$ \\
\hline & CV-4 & $\mathbf{E}-\mathrm{V}---\mathrm{AYS}--\mathrm{SIIRS}-\mathrm{Y} \mathbf{F}-$ \\
\hline & CV-5 & $\mathbf{E}----S---S Y N-I-\mathbf{F L}-\mathbf{F K}$ \\
\hline & CV-6 & $\mathbf{E}-\mathrm{V}---\mathrm{A}-\mathrm{SN}-\mathrm{SI}--\mathbf{F}-\mathrm{Y} \mathbf{F M}$ \\
\hline & CV-7 & $\mathbf{E A}---S A-S S-N I S-\mathbf{F}-Y-M$ \\
\hline & CV-8 & $\mathbf{E}-----A Y S S Y S I I R \mathbf{S}--\mathbf{F}-$ \\
\hline & CV-9 & $\mathbf{E A}---\mathrm{TA}-\mathrm{NN}--\mathrm{IS}-\mathbf{F}-\mathrm{Y} \mathbf{F M}$ \\
\hline \multirow[t]{12}{*}{ PKA } & CV-17 & E-----T-SSYS-S-F-YFM \\
\hline & CV-18 & EA---SAYSS-SISRF-YFM \\
\hline & CV-19 & $\mathrm{E}----\mathrm{S}---\mathbf{S} \mathrm{Y}--\mathbf{S}-\mathbf{F}-\mathbf{Y}-\mathrm{M}$ \\
\hline & CV-20 & $-A---S--S \mathbf{S}-S-\mathbf{S}-\mathbf{F}-\mathbf{Y}-\mathrm{M}$ \\
\hline & CV-21 & $\mathrm{EA}---\mathrm{SA}--\mathbf{S}-\mathrm{S}-\mathbf{S R F}-\mathbf{Y} F \mathrm{M}$ \\
\hline & CV-22 & $-----S T-S-Y S I S-F-Y F M$ \\
\hline & CV-23 & $\mathrm{E}----\mathrm{GFLHQL}-----\mathrm{L}-\mathrm{FK}$ \\
\hline & CV-24 & $E----S--S-Y-I$ SRFLYFM \\
\hline & CV-25 & $-----\mathrm{SA}--\mathbf{S}-\mathrm{NI} \mathbf{S} \mathrm{R}--\mathbf{Y}-\mathrm{M}$ \\
\hline & CV-26 & $\mathrm{E}-------\mathrm{S} \mathbf{S Y}-\mathrm{I} \mathbf{S R F}--\mathrm{FM}$ \\
\hline & CV-27 & $--------\mathrm{SN}-\mathrm{NISRF}--\mathrm{FM}$ \\
\hline & CV-28 & $-\mathrm{A}---\mathrm{SA}-\mathrm{N} \mathbf{S}-\mathrm{SISRF}-\mathbf{Y}-\mathrm{M}$ \\
\hline
\end{tabular}

${ }^{a_{H}}$ Hyphens indicate wild-type residues. Residues strongly preferring the homologous substitution for each selection are highlighted in bold (bold italics in Table 1).

were prepared. The potential for oligomerization by each truncated CSD variant was evaluated through the oligomer complementation assay, which tests binding in the presence of added free CSD. Like full-length CSD, addition of chemically synthesized CSD to most truncated phage-displayed CSD variants could enhance the apparent affinity for PKA and eNOS. However, oligomer complementation with truncated CSD variants revealed that $\mathrm{N}$-terminal CSD residues are more critical for oligomer formation than C-terminal CSD residues (Figure 2, panels $\mathrm{c}$ and $\mathrm{d}$ ). Also, the $\mathrm{N}$-terminal half of CSD was more strongly conserved over subtle homologous mutations than the C-terminal half of CSD during homologue shotgun scanning. Thus, the N-terminus of CSD is required for oligomerization, and the failure of N7-CSD and N5-CSD to mediate oligomer complementation demonstrates that avidity-enhanced binding requires 
additional binding sites along the length of the peptide. The data are most consistent with a model for the PKA- or eNOS-CSD complex whereby the first PKA- or eNOS-CSD interaction is strengthened by conformational rigidification through addition of CSD peptides to the complex.

Functional Implications of CSD Oligomers. Experiments reported here parse CSD side-chain contributions to caveolin binding to both PKA and eNOS. However, CSD inhibition and binding can be uncorrelated. NOS inhibition assays, for example, measure the conversion of oxy-hemoglobin to ferric met-hemoglobin owing to the reaction between NOS-generated NO and oxy-hemoglobin. In preliminary, single point studies, CSD, CV-1, CV-2, and CV-6 all inhibited eNOS to approximately the same degree at a $10 \mu \mathrm{M}$ concentration. Furthermore, full-length CSD is required for inhibition but not binding; the selection experiments reported here focused on optimization of binding and failed to automatically improve the inhibitory activity. It follows that CSD oligomerization is likely necessary for eNOS inhibition, because self-associated CSD might more effectively disrupt electron transfer from the reductase domain to the heme domain of eNOS. Other conserved residues identified by shotgun scanning could also contribute to CSD oligomerization and eNOS inhibition.
Hemodynamic forces, such as shear stress and pressure in blood vessels, can cause an immediate activation of eNOS without an increase in eNOS expression levels $(23,24)$. Disruption of caveolin-1 oligomerization by shear stress and pressure might permit access to eNOS by a positive allosteric modulator, such as calmodulin. The correlation between CSD oligomerization and eNOS inhibition reported here also suggests a direct route to eNOS activation. Shear stress and other forces known to disrupt CSD oligomerization could prevent inhibition of eNOS by CSD, thus immediately activating NO production; this release, in turn, relaxes blood vessels. This mechanism would provide an immediate response to shear stress and blood pressure, coupling a mechanical event to an underlying molecular mechanism.

In summary, we demonstrate a combination of phagedisplayed homologue shotgun scanning, oligomer complementation, and DLS to uncover CSD residues mediating self oligomerization, protein binding, and enzymatic inhibition. The oligomerization and deoligomerization mechanism proposed here (Figure 3) could govern other caveolin-regulated cell signaling proteins. In addition, the double barrel shotgun scanning strategy introduced here could provide valuable tools for dissecting other multimeric receptor-ligand interactions.

\section{METHODS}

CSD Peptide Synthesis and Expression. The CSD peptide was synthesized manually on a $0.3 \mathrm{mmol}$ scale. [5-(4'-Fmocaminomethyl-3',5'-dimethoxy-phenoxy)-valeric acid]/poly(ethylene glycol)/polystyrene (Fmoc-PAL-PEG-PS) resin was used to install a carboxyamide at the C-terminus of the synthesized peptide. The peptide was deprotected and cleaved with $95 \%$ trifluoroacetic acid (v/v, TFA), $2.5 \% \mathrm{v} / \mathrm{v}$ water, and $2.5 \%$ triisopropylsilane (v/v, TIS) applied for $3 \mathrm{~h}$. Peptide purification was performed by automated preparative LC/MS (Waters) with a water/acetonitrile gradient containing $0.1 \% \mathrm{v} / \mathrm{v}$ TFA. The observed mass $(\mathrm{m} / \mathrm{z})$ for CSD matched expected values. CSD: 1259.4 $\left(\mathrm{MH}^{2+}\right)$ (calculated mass, 1259.5$)$ and $840.2\left(\mathrm{MH}^{3+}\right)$ (calculated mass, 840.3). A vector for the expression of CSD fused to maltose binding protein (CSD-MBP) was constructed by mutagenesis of the pMAL vector with the pMAL-CSD oligonucleotide as described previously (25). The CSD-MBP vector was transformed into $E$. coli ER2507 for expression at $37^{\circ} \mathrm{C}$ induced by the addition of $500 \mu$ M IPTG for $4 \mathrm{~h}$. Standard purification protocols applied an amylose column. SDS-PAGE and MALDI TOF confirmed expression of CSD-MBP as a single band with the expected mass range.

Construction of the Homologue Shotgun Scanning Library. The homologue shotgun scanning library was constructed using a previously described mutagenesis method $(25,26)$ with phagemid pM1165a as template (16).
Biopanning Phage-Displayed Peptides Binding to eNOS and PKA. The homologue shotgun scanning library was cycled through serial rounds of selection for eNOS binding. Ninety-sixwell Maxisorp plates (Nunc) were coated overnight at $4{ }^{\circ} \mathrm{C}$ with

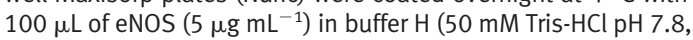
$150 \mathrm{nM} \mathrm{NaCl}, 2 \mathrm{mM}$ imidazole, $0.1 \mathrm{mM}$ DT, $0.1 \mathrm{mM}$ EDTA, $10 \mu \mathrm{M}$ tetrahydrobiopterin $\left(\mathrm{H}_{4} \mathrm{~B}\right)$, and $10 \% \mathrm{w} / \mathrm{v}$ glycerol). The coating solution was removed, and the plates were blocked for 15 min with a $0.2 \% \mathrm{w} / \mathrm{v}$ solution of either bovine serum albumin (BSA) or casein in buffer B (50 mM Tris- $\mathrm{HCl}, \mathrm{pH} 7.8,100 \mathrm{mM}$ $\mathrm{NaCl}, 2 \mathrm{mM}$ imidazole). After the plates were washed three times with wash buffer $(0.02 \% \mathrm{w} / \mathrm{v}$ Tween-20 in Tris-HCl buffer), 100 $\mu \mathrm{L}$ of the phage library in sample buffer $(50 \mathrm{mM}$ Tris- $\mathrm{HCl}, \mathrm{pH} 7.8$, $100 \mathrm{mM} \mathrm{NaCl}, 2 \mathrm{mM}$ imidazole, and 10\% w/v glycerol) was transferred to 24 of the coated wells. After $1 \mathrm{~h}$, the plate was washed five times with wash buffer. Phage were eluted by addition of $100 \mu \mathrm{L}$ of $100 \mathrm{mM} \mathrm{HCl}$ and vigorous shaking for $5 \mathrm{~min}$. The eluted phage were immediately neutralized with $33 \mu \mathrm{L}$ of $1 \mathrm{M}$ Tris- $\mathrm{HCl}(\mathrm{pH}$ 8). Half of the eluted phage solution was used to infect $15 \mathrm{~mL}$ of XL-1 Blue cells $\left(\mathrm{OD}_{550} 0.5-1.0\right)$. After $20 \mathrm{~min}$ of shaking at $37^{\circ} \mathrm{C}$, the infected cells were transferred to $400 \mathrm{~mL}$ of 2YT supplemented with $50 \mu \mathrm{g} \mathrm{mL}^{-1}$ ampicillin and $10^{10}$ phage $\mathrm{mL}^{-1} \mathrm{M} 13-\mathrm{K} 07$ helper phage. After $16 \mathrm{~h}$ of incubation at $37^{\circ} \mathrm{C}$, phage were harvested from the culture by standard methods and resuspended in $2 \mathrm{~mL}$ of sample buffer. After the first round of selection, biopanning was conducted at 1/12th of the scale described above, and repeated five times. Biopanning of 
the homologue shotgun scanning library against PKA was performed as described previously (15).

DLS Measurements. DLS was used to examine oligomerization of both CSD free peptide and CSD-MBP. Measurements at RT were performed on a Protein Solutions Dyna Pro 99 instrument using DYNAMICS software. Samples were centrifuged two times at $18,000 \mathrm{~g}$ for $20 \mathrm{~min}$ immediately prior to measurement to remove insoluble aggregates and dust. Each sample was studied at several concentrations ranging from 3 to $1 \mathrm{mM}$.

NOS- or PKA-CSD Binding Assay. A phage-based ELISA was used to examine binding to PKA, eNOS, and nNOS by CSD and variant peptides. Maxisorp 96-well plates were coated with 100 $\mu \mathrm{L}$ of protein solution (PKA, eNOS, nNOS, and nNOS heme domain) diluted to $5 \mu \mathrm{g} \mathrm{mL}^{-1}$ in buffer $\mathrm{H}$ for NOS or PBS for PKA. After overnight incubation at $4{ }^{\circ} \mathrm{C}$, the coating solution was removed, and the plates were blocked for $15 \mathrm{~min}$ with a $0.2 \% \mathrm{w} / \mathrm{v}$ solution of BSA in buffer B (NOS) or PBS. Negative control wells, which were not coated with protein, were coated with the BSA solution. After the plates were rinsed with wash buffer three times, a solution of phage-displayed peptides was added to both protein-coated wells and BSA control wells. Plates then were incubated at $4{ }^{\circ} \mathrm{C}$ with gentle shaking for $1 \mathrm{~h}$. After the plates were washed five times with wash buffer, the plates were incubated $30 \mathrm{~min}$ with horseradish peroxidase (HRP)conjugated anti-M13 antibody $(1: 3,000)$ dissolved in PBS containing $0.02 \% \mathrm{w} / \mathrm{v}$ Tween-20, $0.2 \% \mathrm{w} / \mathrm{v}$ BSA. The plate was washed five times with wash buffer, before incubation for 10 min with $2 \mathrm{mg} \mathrm{mL}^{-1} o$-phenylenediamine dihydrochloride/ $0.02 \% \mathrm{w} / \mathrm{v} \mathrm{H}_{2} \mathrm{O}_{2}$ solution in citric acid buffer $(50 \mathrm{mM}$ citric acid, $50 \mathrm{mM} \mathrm{Na} \mathrm{HPO}_{4}, \mathrm{pH}$ 5.0). Reactions were quenched with $100 \mu \mathrm{L}$ of $0.1 \mathrm{M} \mathrm{HCl}$ before saturation was reached. The absorbance of the solution at $492 \mathrm{~nm}$ was measured by a microtiter plate reader ( $\mu$ Quant, Bio-Tek). All solutions of phage-displayed peptides were prepared from overnight cultures grown in parallel under identical conditions, and the relative binding affinities were compared on the same ELISA plate. For spot assays of individual selectants from the homologue shotgun scanning library, a similar format was used, except clones were grown in $5 \mathrm{~mL}$ scale. The HRP activity for clones identified as positive binders was at least 4 -fold over background binding to BSA.

For the CSD oligomer complementation assay, different concentrations of chemically synthesized CSD were added to each of the phage solutions immediately prior to transfer to the targetcoated plates.

NOS Inhibition Assays. A standard hemoglobin capture assay (27) with addition of competitor peptides at $10 \mu \mathrm{M}$ concentration was used to assess eNOS inhibition.

Acknowledgment: We thank $\mathrm{H}$. Li for providing eNOS. We thank S. Taylor and M. Deal (Howard Hughes Medical Institute and University of California, San Diego) for providing PKA. This work was supported financially by the Arnold and Mabel Beckman Foundation (G.A.W.), the National Institutes of Health, National Institute of General Medical Sciences (Grant 1 R01 GM078528-01 to G.A.W. and Grant R01 GM57353 to T.L.P.), and the University of California's Biotechnology Research and Education Program (training grants awarded to both K.M. and A.M.L.).

\section{REFERENCES}

1. Chaurasia, G., Iqbal, Y., Hanig, C., Herzel, H., Wanker, E. E., and Futschik, M. E. (2007) UniHI: an entry gate to the human protein interactome, Nucleic Acids Res. 35, D590-D594.

2. Vajdos, F. F., Adams, C. W., Breece, T. N., Presta, L. G., de Vos, A. M., and Sidhu, S. S. (2002) Comprehensive functional maps of the antigen-binding site of an anti-ErbB2 antibody obtained with shotgun scanning mutagenesis, J. Mol. Biol. 320, 415-428.
3. Weiss, G. A., Watanabe, C. K., Zhong, A., Goddard, A., and Sidhu, S. S. (2000) Rapid mapping of protein functional epitopes by combinatorial alanine scanning, Proc. Natl. Acad. Sci. U.S.A. 97, 8950-8954.

4. Liu, P., Rudick, M., and Anderson, R. G. (2002) Multiple functions of caveolin-1, J. Biol. Chem. 277, 41295-41298.

5. Bender, F. C., Reymond, M. A., Bron, C., and Quest, A. F. (2000) Caveolin-1 levels are down-regulated in human colon tumors, and ectopic expression of caveolin-1 in colon carcinoma cell lines reduces cell tumorigenicity, Cancer Res. 60, 5870-5878.

6. Koleske, A. J., Baltimore, D., and Lisanti, M. P. (1995) Reduction of caveolin and caveolae in oncogenically transformed cells, Proc. Natl. Acad. Sci. U.S.A. 92, 1381-1385.

7. Razani, B., Woodman, S. E., and Lisanti, M. P. (2002) Caveolae: from cell biology to animal physiology, Pharmacol. Rev. 54, 431- 467.

8. Garcia-Cardena, G., Fan, R., Stern, D. F., Liu, J., and Sessa, W. C. (1996) Endothelial nitric oxide synthase is regulated by tyrosine phosphorylation and interacts with caveolin-1, J. Biol. Chem. 271, 27237-27240.

9. Ju, H., Zou, R., Venema, V. J., and Venema, R. C. (1997) Direct interaction of endothelial nitric-oxide synthase and caveolin-1 inhibits synthase activity, J. Biol. Chem. 272, 18522-18525.

10. Razani, B., Rubin, C. S., and Lisanti, M. P. (1999) Regulation of cAMP-mediated signal transduction via interaction of caveolins with the catalytic subunit of protein kinase A, J. Biol. Chem. 274, 26353-26360.

11. Andre, I., Kesvatera, T., Jonsson, B., and Linse, S. (2006) Salt enhances calmodulin-target interaction, Biophys. J. 90, 2903-2910.

12. Bayley, P. M., Findlay, W. A., and Martin, S. R. (1996) Target recognition by calmodulin: dissecting the kinetics and affinity of interaction using short peptide sequences, Protein Sci. 5, 1215-1228.

13. Houdusse, A., Gaucher, J. F., Krementsova, E., Mui, S., Trybus, K. M., and Cohen, C. (2006) Crystal structure of apo-calmodulin bound to the first two IQ motifs of myosin $\mathrm{V}$ reveals essential recognition features, Proc. Natl. Acad. Sci. U.S.A. 103, 19326-19331.

14. Ye, Q., Li, X., Wong, A., Wei, Q., and Jia, Z. (2006) Structure of calmodulin bound to a calcineurin peptide: a new way of making an old binding mode, Biochemistry 45, 738-745.

15. Levin, A. M., Coroneus, J. G., Cocco, M. J., and Weiss, G. A. (2006) Exploring the interaction between the protein kinase A catalytic subunit and caveolin-1 scaffolding domain with shotgun scanning, oligomer complementation, NMR, and docking, Protein Sci. 15, 478-486.

16. Murase, K., Morrison, K. L., Tam, P. Y., Stafford, R. L., Jurnak, F., and Weiss, G. A. (2003) EF-Tu binding peptides identified, dissected, and affinity optimized by phage display, Chem. Biol. 10, 161-168.

17. Avrantinis, S. K., Stafford, R. L., Tian, X., and Weiss, G. A. (2002) Dissecting the streptavidin-biotin interaction by phage-displayed shotgun scanning, ChemBioChem 3, 1229-1234.

18. Sato, K., Simon, M. D., Levin, A. M., Shokat, K. M., and Weiss, G. A. (2004) Dissecting the engrailed homeodomain-DNA interaction by phage-displayed shotgun scanning, Chem. Biol. 11, 1017-1023.

19. Cochran, J. R., Kim, Y. S., Lippow, S. M., Rao, B., and Wittrup, K. D. (2006) Improved mutants from directed evolution are biased to orthologous substitutions, Protein Eng. Des. Sel. 19, 245-253.

20. Levin, A. M., and Weiss, G. A. (2006) Optimizing the affinity and specificity of proteins with molecular display, Mol. Biosyst. 2, 49-57.

21. Fernandez, I., Ying, Y., Albanesi, J., and Anderson, R. G. (2002) Mechanism of caveolin filament assembly, Proc. Natl. Acad. Sci. U.S.A. 99, 11193-11198.

22. Bernatchez, P. N., Bauer, P. M., Yu, J., Prendergast, J. S., He, P., and Sessa, W. C. (2005) Dissecting the molecular control of endothelial NO synthase by caveolin-1 using cell-permeable peptides, Proc. Natl. Acad. Sci. U.S.A. 102, 761-766. 
23. Gratton, J. P., Fontana, J., O’Connor, D. S., Garcia-Cardena, G., McCabe, T. J., and Sessa, W. C. (2000) Reconstitution of an endothelial nitric-oxide synthase (eNOS), hsp90, and caveolin-1 complex in vitro. Evidence that hsp90 facilitates calmodulin stimulated displacement of eNOS from caveolin-1, J. Biol. Chem. 275, $22268-22272$.

24. Sato, Y., Sagami, I., and Shimizu, T. (2004) Identification of caveolin1-interacting sites in neuronal nitric-oxide synthase. Molecular mechanism for inhibition of NO formation, J. Biol. Chem. 279, 8827-8836.

25. Sidhu, S. S., and Weiss, G. A. (2004) in Oligonucleotide-directed construction of phage display libraries (Lowman, H. L., and Clackson, T., Eds.), Oxford University Press, pp 27-41.

26. Sidhu, S. S., Lowman, H. B., Cunningham, B. C., and Wells, J. A. (2000) Phage display for selection of novel binding peptides, Meth ods Enzymol. 328, 333-363.

27. Kelm, M., Feelisch, M., Spahr, R., Piper, H. M., Noack, E. A., and Schrader, J. (1988) Quantitative and kinetic characterization of nitric oxide and EDRF released from cultured endothelial cells, Biochem. Biophys. Res. Commun. 154, 236-244. 